\section{Book review}

McLachlan's Handbook of Diagnosis and Treatment of Venereal Diseases. By A. S. Grimble. 5th edition, 1969. Pp. 213, 161 figs. Livingstone, London and Edinburgh (50s.)

The author is to be congratulated on maintaining the high standards of clinical descriptions, differential diagnoses, and histopathology, which have always typified McLachlan's Handbook. This useful book should be studied and learnt by all those who intend to practise in venereology and any of its allied subjects. The limited bibliographies at the end of the chapters are quite adequate for a book of this size.

This is not an easy book to read; one is constantly being referred back and forth through the text in search of related material and unfortunately too many of the references are incorrect. As an example, on p. 143 the reader is referred to p. 195 , and from there immediately back to p. 142 . The illustrations, only six of which are in colour, are too small for clarity although some clinical entities are illustrated by two figures when one would have sufficed and there are errors in the descriptions under some of them.

Many would feel that Chlamydia oculogenitale (p. 1) should not be considered a virus and that Donovania granulomatis (p. 3) is a member of the Klebsiella group of bacteria. It might also be pointed out that psittacosis was the most likely cause for some patients in east London having serum complement-fixing antibodies to lymphogranuloma venereum (p. 2).

Certain other points require note: oxygen should be mentioned in the treatment of anaphylaxis (p. 41); superficial glossitis (fig. 79) is a misnomer, the condition is a glossitis profunda; Horner's syndrome (p. 66) is classically associated with an aneurysm of the transverse not of the ascending aorta; loss of vibration sense is worth including among the sensory changes in tabes dorsalis (p. 78); syphilis usually causes late rather than early miscarriages (p. 93).
It is disappointing to find that this edition perpe- $\frac{\bar{m}}{\overline{\frac{D}{2}}}$ tuates that confusion of former days between the very $\stackrel{\varnothing}{\Omega}$ rare metastatic complications of gonorrhoea and the clinical manifestations of Reiter's disease. One would $\vec{A}$ have thought that, with the criterion for the diagnosis of gonorrhoea at any site being the isolation of $N \cdot \vec{\omega}$ gonorrhoeae therefrom, such prevarication would be $\frac{O}{6}$ unnecessary.

In the diagnosis of Trichomonas vaginalis (p. 140) के phase-contrast microscopy has the advantage over $-\overrightarrow{-}$ dark-ground in that the substage lens is kept dry, $\stackrel{\infty}{\oplus}$ while in the fluorescent antibody stain for $N$.응 gonorrhoeae (p. 203) naphthalene black has super- $\rightarrow$ seded rhodamine. Thayer and Martin's medium or T one of its modifications should be mentioned in cul- $\frac{\mathbb{D}}{O}$ tural methods to identify $N$. gonorrhoeae (p. 203).

Some might argue that there are newer, less irritant, and more effective lotions than $1: 8,000$ Pot. $\vec{\varphi}$ permanganate (p. 40, et al.) to apply in the various conditions for which it is recommended, that sulphadimidine, which is more soluble, is safer than sulphatriad (pp. 99 and 104), and that arsenical pessaries (p. 148) should not be used nowadays in the treatment of non-specific vaginitis, since there are a number of $\frac{\emptyset}{\varnothing}$ other less dangerous preparations available.

There are some discrepancies in the text, thus the $\overrightarrow{\overrightarrow{0}}$ lymph drainage of the upper vagina is stated incor- 3 rectly on p. 16 to be the inguinal glands and correctly on p. 102 to the pelvi-rectal groups while erythema? multiforme and Stevens-Johnson syndrome are con- on sidered as separate entities on p. 144 and identical on p. 176.

Notwithstanding these criticisms and considering $\delta$ that the majority of the errors could have been 3 remedied by careful proof-reading, this handbook 0 remains a very good primer although one doubts it being "appreciated by all persons above the age of $\frac{}{0}$ puberty".

C. B. S. Schofield.

\title{
International Union against the Venereal Diseases and Treponematoses
}

26th GENERAL ASSEMBLY

Budapest, fune 11-15, 1969

As it has proved impracticable in the past to publish the full proceedings of the I.U.V.D.T. assemblies separately in book form, it has been decided to devote the April issue of the British fournal of Venereal Diseases to papers given in English, and to include the periodical Bulletin of the I.U.V.D.T. Those papers given in other languages will be appearing in successive issues of the French journal Prophylaxie sanitaire et morale.

It is emphasized that the number of papers presented at Budapest far exceeded the capacity of both journals to accept for publication; accordingly only selected papers will be included. 